\title{
Comentários - Considerações sobre o Artigo Estratégia e Gestão Estratégica das Empresas: um Olhar Histórico e Crítico
}

\section{Reflections on the Article Strategy and Strategic \\ Management of Companies: a Historical and Critical Review}

Carlos Osmar Bertero *

Doutor pela Cornell University, Estados Unidos. Professor da FGV-EAESP, São Paulo/SP, Brasil. 
Atendo ao gentil convite para comentar o artigo em referência. Os autores merecem cumprimentos pelo aguçado senso crítico e por se recusarem a aceitar os desenvolvimentos do campo da Estratégia Empresarial e da Gestão Estratégica dos Negócios da maneira como vem ocorrendo nas últimas décadas e mais especificamente a partir dos anos setenta e com base predominantemente na academia norte-americana. Questões decisivas e importantes para a área são levantadas. Não apenas a delimitação do campo em termos científicos, como também a questão difícil, delicada e penosa entre a abordagem acadêmica, ou da construção de uma ciência ou de uma filosofia da estratégia e suas vinculações à prática da estratégia.

Se bem entendi o itinerário da estratégia, como apresentado pelos autores, houve nalgum momento um descarrilamento e a estratégia enveredou por uma trilha de perversidade e perpetração de um círculo vicioso de ineficácia e desserviço, não só às empresas, mas à sociedade em geral. Dessa forma, para usar um termo ao gosto da atual retórica, todos os stakeholders são igualmente desservidos. O ceticismo dos autores não se limita a abordagens específicas da estratégia, como o posicionamento e a teoria baseada em recursos, mas se estende ao tratamento da estratégia como campo científico. Acreditam e advogam que a gestão estratégica só pode ser resgatada, se for direcionada para o universo da política e da filosofia. Desse modo, a estratégia precisaria retomar uma dimensão clássica de ser, acima de tudo, uma sabedoria, e o caminho para a sabedoria não passaria pela ciência.

A razão fundamental, parodiando um pouco Emanuel Kant, seria simplesmente que a sabedoria é sintética, enquanto a ciência é analítica. O sentido somente se descobre agregando, ao passo que a ciência atua necessariamente decompondo e fragmentando. A ciência não pode lidar com o universo e com as questões da estratégia, pelo fato de ser incapaz de lidar com a complexidade. O mundo da estratégia é inegavelmente complexo e, para lidar com a complexidade estratégica, outra abordagem e quiçá uma nova disciplina se faz necessária, a qual nada tem que ver com os modelos, teorias e propostas, até o momento atual produzidas, e que vem norteando a prática e também os trabalhos acadêmicos.

Apontam como importante e lamentável nos descaminhos da gestão estratégica a financeirização, em virtude da qual se implanta uma visão necessariamente imediatista dos negócios e da própria empresa e o atendimento prioritário dos interesses do acionista, que é um dos stakeholders; mas que, de fato, é erguido à condição de centro da empresa e o seu principal beneficiário. Esta abordagem impede a reflexão estratégica, comprometendo qualquer possibilidade de reto- 
mada de uma via saudável para a área de atuação prática ou profissional e da própria estratégia enquanto conhecimento. A financeirização é reforçada e aprimorada pelas pressões do mercado que são sentidas pelos executivos e que são assumidas pelas empresas de consultoria que aprimoram e perpetuam o modelo.

Os autores sintetizam sua crítica, afirmando que a estratégia se tornou uma ciência amoral e descontextualizada e que isto a conduziu a tornar-se imoral e ineficaz. Seus principais pecados: a área foi dominada por financistas e economistas; o domínio dos campos científicos tradicionais elimina a possibilidade de integração; a concentração do poder nas empresas torna a ciência inútil; as firmas de consultoria atuam como potenciadoras do movimento. Para tantos descaminhos haveria possibilidade de resgatar a estratégia? Acreditam que seria desde que se reconhecessem e se atuassem em conformidade com os seguintes pontos: a estratégia é uma ciência do complexo e por isto incompatível com reduções analíticas exacerbadas; a estratégia é uma ciência dialógica paradoxal e do ago-antagonismo; a estratégia deve levar em consideração os jogos recíprocos entre os dispositivos ou instrumentos de gestão e as filosofias que os sustentam; a estratégia deve continuar a obsessão da finalidade; a estratégia deve colocar os vários tipos de risco no centro de suas preocupações. E finalmente a estratégia deve ser repensada com base na moral e na política.

Os caminhos propostos pelos autores os colocam exatamente em contradição com aquilo que se desenvolveu até o momento em termos de estratégia. $\mathrm{Na}$ verdade o que a área preza é a sua transformação de uma prática e de um curso ensinado em escolas de administração de negócios, que se apoiavam apenas em apresentações e discussões de casos, de preferência de empresas bem sucedidas, num campo que se delimitou como seminalmente científico. O movimento começou ainda em Harvard com Keneth Andrews e depois foi gradativamente sendo expandido com o posicionamento e críticas que lhe foram feitas, mas sempre levando em conta o fato de que todos estavam contribuindo para gerar alguma teoria, condição indispensável para que um conhecimento seja considerado científico e não mais uma apresentação de casos.

Mesmo os que se encontram no mainstream reconhecem o caráter ainda incipiente da estratégia enquanto ciência e teoria, mas acreditam que se deve prosseguir numa senda científica. O capítulo de Richard Whipp, redigido para a primeira edição do Handbook de Estudos Organizacionais, propõe um roteiro em que aponta para a ainda reduzida contribuição para a estratégia daquilo que vem das ciências sociais. Na verdade não há como negar que a maioria das elaborações em estratégia se apóia na economia. Isto pode ser constatado na abordagem de posicionamento que faz uso da Organização Industrial, na teoria baseada 
em recursos, herdeira da teoria da firma e ainda nas teorias da agência, dos custos de transação e mesmo na teoria da escolha estratégica.

A área de administração como um todo e não apenas a de gestão estratégica, trabalhou com o pressuposto de que a ciência em administração é não apenas possível, mas desejável. Adotou-se o modelo científico que se desenvolveu na tradição filosófica e científica ocidental, a partir das grandes transformações que tiveram como principais responsáveis Francis Bacon, Galileo, Descartes e Newton. O conhecimento leva ao entendimento para permitir o controle e a intervenção. Daí o fato de que embora o ocidente não tenha sido o berço do conhecimento foi de um tipo específico de conhecimento que denominamos como ciência e que gerou aplicações sob a forma de tecnologia. A cultura islâmica e a chinesa foram admiráveis e durante muitos séculos consideradas superiores à então tosca Europa Ocidental. Mas, curiosamente, não foi no bojo daquelas culturas que se desenvolveu a ciência, nem a tecnologia. Quando descobertas nelas ocorreram, não tiveram a difusão que conheceram no ocidente. Os pioneiros da administração não por acidente a denominaram de administração científica (scientific management) e acreditavam que seria possível descobrir leis, princípios gerais e elaboração de teorias que se aplicariam universalmente. Exatamente há quase cinco séculos isto vinha acontecendo no domínio das ciências da natureza.

Embora isto possa parecer superado pela aparição, na segunda metade do século XX, das várias propostas contingenciais, não há como negar que áreas importantes da administração, como marketing, finanças e operações, continuam a trabalhar com este modelo de ciência. Dessa maneira, permanecem avessas a repensar-se fora de um padrão de ciência como desenvolvido na tradição ocidental.

Não me parece correto atribuir a imoralidade e a ineficácia da estratégia ao fato de querer tornar-se científica. A ciência não me parece incompatível com a moralidade. Acredito que os autores estão corretos ao deplorarem práticas de negócios e muitas práticas noutras esferas da vida como lamentáveis e potencialmente suicidas. Mas elas nos remetem a outro registro, que é o da ética, da filosofia e para alguns até mesmo da religião e da teologia. Mas não é necessário abdicar da ciência para ser moral, sábio e eficaz. Embora não seja um entusiasta da ciência, no estilo do iluminismo e dos ideais progressistas que marcaram o século XIX, não me parece que necessitemos da ciência para ser morais ou imorais.

Quero aqui retomar o registro kantiano e usar a divisão dos juízos em factuais e valorativos. Segundo nosso filósofo de Köenigsberg juízos de fato são os que comportam uma comprovação empírica e os de valor onde tal comprovação é 
impossível. Sem adentrar nas questões da epistemologia kantiana, mas utilizando a sua classificação dos juízos, proponho que se reconheça que a estratégia usa necessariamente os dois tipos de juízo, os de fato e os de valor. Na verdade o que os nossos autores chamam de científico na estratégia é aquela parte que faz uso de juízos factuais que, segundo Kant, são os utilizados pela ciência. Se você quiser usar o modelo de positioning de Michael Porter, certamente utilizará juízos factuais para realizar uma análise do ramo ou do setor (industry analysis). Igualmente suas simulações sobre mercados e projeções orçamentárias e de relatórios financeiros serão também feitas com juízos factuais. O Business Plan é deliberadamente factual. Mas sabemos que as decisões estratégicas não são tomadas apenas com base em juízos factuais, sendo muitas vezes tomadas em clara contradição com tais juízos. Mas estratégias são decididas com base em juízos de valor. O mundo de valores e das crenças dos tomadores de decisões estratégicas são fundamentais para que possamos entender os caminhos estratégicos. Portanto a estratégia não se explica e não se resolve em nível puramente factual, mas demanda o nível valorativo. De onde a correção de uma das designações passadas da área, Business Policy.

Mas há coisas fáceis de propor e difíceis de realizar. E o resgate da estratégia, enquanto área simultaneamente factual e valorativa, não é tarefa expedita. Ainda não conseguimos nem mesmo consolidá-la no terreno factual, na medida em que muitas ciências estão ausentes da teorização estratégica, especialmente as ciências comportamentais e sociais, exceto a economia.

Mas uma dimensão importante da estratégia e da gestão estratégica que parece ter escapado aos nossos autores é o da estratégia enquanto prática. A dimensão prática da estratégia esteve presente no início do ensino da disciplina, quando professores de estratégia não eram necessariamente educados escolarmente em administração. A preferência era por pessoas que já possuíssem experiência como executivos sênior no mundo dos negócios. Algumas escolas tinham a própria figura do executive in residence. Mas na medida em que transformações ocorreram e as escolas de administração de negócios dos Estados Unidos tiveram que conquistar respeitabilidade acadêmica, portadores de titulação começaram a preencher os quadros docentes. Foi uma das maneiras como a lacuna entre teoria e prática começou a ser cavada no mundo da administração. A estratégia enquanto prática não pode permanecer uma dimensão esquecida. Atualmente esta lacuna é tão clara e lamentável que teríamos dificuldade em imaginar um executivo lendo algum periódico de nível internacional A de gestão estratégica. Mas a dimensão prática não pode ser eliminada e não há razão para se excluir da prática a dimensão científica da estratégia. 
O texto de nossos autores é bem-vindo num momento em que a revisão e a reflexão são necessárias. Há consciência de que a humanidade corre sérios riscos. O debate em torno da violência contra o ambiente, contra comunidades integra a ordem do dia. Empresas se tornaram organizações absolutamente centrais no mundo contemporâneo. Os pioneiros do capitalismo teriam dificuldade em imaginar que empresas viriam a ter um papel tão importante e destacado na condução dos afazeres humanos. A tentação é de reconhecer que sua influência, poder e importância transcendem de muito a produção de bens e serviços e sua comercialização. Conseqüientemente não se pode relegar a gestão estratégica da empresa ao mundo dos juízos de fato. Valores são imprescindíveis para que a estratégia resgate sua vocação de discutir e propor fins e objetivos. A teleologia deve ser recebida como a filha pródiga para que a estratégia não permaneça como pura instrumentalidade. 